\title{
Limiting professional trajectories: a dual narrative study in Chinese language education
}

\author{
Robyn Moloney ${ }^{1 *}$ (D) and Danping Wang ${ }^{2}$
}

\author{
* Correspondence: \\ robyn.moloney@mq.edu.au \\ ${ }^{1}$ School of Education, Faculty of \\ Human Sciences, Macquarie \\ University, Balaclava Rd, North Ryde, \\ NSW 2109, Australia \\ Full list of author information is \\ available at the end of the article
}

\begin{abstract}
Introduction: The globally expanding community of educators involved in the teaching of Chinese as a Foreign Language (CFL) is being pushed to adapt to diverse educational contexts, engendering tension and dislocation. There has been limited success in efforts to modernise practice in the teaching of Chinese, with subsequent urgent calls for both a fresh approach to innovation, and for a better understanding of the nature of teacher experience in the professional community. This article reports a project which employed self-study to investigate, through analysis of reflective narratives, two career trajectories associated with Chinese as a foreign language.

Results: The analysis of the narratives uncover issues of identity and power, in the shaping of the participants's practice and professional trajectories. The analysis provides illustration of how limitation in professional participation can result in limitation of innovative practice. The investigation identifies the formation of new independent decentralised professional communities for CFL.

Conclusions: The study offers recommendations to promote innovative practice which can support more effective teaching and learning.
\end{abstract}

Keywords: Teacher identity, Narrative, Professional trajectory, Community of practice, Chinese pedagogy

\section{Introduction}

As a new and burgeoning professional field, the teaching of Chinese as a foreign language is seeking global dissemination and popularity similar to that established by English as a Foreign/Second Language (EFL/ESL) over the last century. In EFL/ESL, appropriate pedagogies and theoretical research paradigms have been established and accepted in diverse contexts, and are often referred to as guidelines for other foreign language teaching and research.

This study is wary of framing cultural comparisons which may produce essentialized assumptions about "Chinese pedagogy", and aware of the emerging critique (Dervin 2011) of studies and teaching practice (Cole and Meadows 2013) which perpetuate fixed understandings of culture, particularly in studies involving Chinese students. And yet, there can be thoughtful recognition of the East-West endeavour (Ma 2014), and the negotiation taking place, in East-West pedagogic and academic shift. That is, a shift

\section{Springer}

(c) 2016 Moloney and Wang. Open Access This article is distributed under the terms of the Creative Commons Attribution 4.0 International License (http://creativecommons.org/licenses/by/4.0/), which permits unrestricted use, distribution, and reproduction in any medium, provided you give appropriate credit to the original author(s) and the source, provide a link to the Creative Commons license, and indicate if changes were made. 
from an alignment with Confucian traditional pedagogic values, to an alignment with the pedagogic practice of schools and universities in contexts like North America, Australia and Europe. This complex network of contrasting educational values and practice is being negotiated in sites such as teacher knowledge and beliefs, in the creation of teaching materials to suit different contexts, and in classrooms in diverse global settings. Stakeholders include teacher educators, teachers, learners, policy designers and textbook-writers, amongst others. Finding a professional trajectory in this complex and conflicted network is a challenging intercultural exercise for all concerned (Ma 2014; Moloney 2013; Moloney and Xu 2012). Issues of power and identity may be closely involved in the conflicted development of new practice, and the charting of professional trajectories. The role and impact of such trajectories is the focus of this article.

While change is inherent to the idea of a professional teaching and academic community (Lave and Wenger 2002), it has been suggested that the process of the modernization of Chinese pedagogy, in particular, may be "associated with confrontations and competition", and "education systems have to undergo a process of modification, adaptation and transformation in a particular socio-cultural context, creating hybrid kinds of pedagogy" (Deng 2011: 561). It has been identified that there is currently very limited success in the modernisation of pedagogical practice in CFL (Chiang 2010; Hu 2002; Orton 2008). Despite political rhetoric about the need for graduates with Chinese language skills, there is, for example, in Australia, a $96 \%$ dropout amongst learners of Chinese, before the final year of secondary school. There is an identified urgent need to recognise and promote modernised innovative CFL teaching practice (Orton 2008; Moloney and Xu 2015).

For the expanding community of Chinese teaching professionals who are involved with innovative pedagogy, however, there remains a struggle for academic recognition of new practice and a problematic trajectory to legitimate professional participation and leadership. Thus, we believe that the examination of career trajectories within CFL education may cast light on productive change in the CFL community, encourage critique within the community, provide support in the negotiation towards effective CFL teaching and learning, so that more innovative practice may emerge. This qualitative project employed self-study methodology and analysis, to investigate, through analysis of reflective narratives, two career trajectories involved with CFL teaching, teacher training and research.

A considerable body of studies has used diverse theoretical approaches and methodologies to explore how individual language educator's beliefs, identity and experiences are related to their practice and their relationship with a professional community (Armour 2004; Canagarajah 2012). Despite the wealth of studies of teacher identity in TESOL and other language study areas, the study of Chinese language teacher identity has only recently emerged as a research priority (Sun 2012; Wang and Du 2014). To capture the function of societal issues in shaping teacher knowledge, qualitative interpretive modes of enquiry have been considered important research tools in the last twenty years (Ben-Peretz 2011). Indeed, according to Kleinsasser (2013) the most prevalent research theme in teacher education is currently that of narrative enquiry and identity. Thus, it is timely that this approach contributes more vigorously to the debates on identity construction involved in problematic trajectories in CFL professional participation (Zhang and Zhang 2015). 


\section{Literature review}

The ideas in this study intersect a number of important research areas, including language teacher identity, narrative research and community of practice, in order to enrich the theoretical vigour of this research.

Understandings of identity have emanated from disciplines of anthropology and sociology but have gained acceptance in studies of education, and language teaching in particular. Varghese et al. (2005) have noted that there are three features of identity process, which have become commonly discussed and considered salient in such studies. Identity is firstly understood as multiple, fluid and often conflicted in nature (Hall 1990), and importantly includes the notion of agency to explain teacher choices and decisions. The second understanding is that identity is always related to social cultural and political contexts (Cummins 1996; Lave and Wenger 2002; Norton 2000). Finally, it is understood that identity is constructed and negotiated through language and ongoing interactions with others (Bucholtz and Hall 2004). Particular issues in studies of language teacher identity have included marginalisation, the position of non-native speaker teachers, and the nature of teacher knowledge.

For all teachers, teaching involves a substantial investment of the self (Goodson 2003). Language teachers in particular position themselves both personally and professionally between two or more languages and cultures (Kanno 2003). These observations and issues have created a diverse research field but, as Varghese et al. (2005) note, do not constitute a coherent theoretical approach. While we acknowledge critique of its limitations in this context (Varghese et al. 2005), discussed below, we have chosen to use Wenger's (1998) framework of the dual process of identity formation. This is described as the result of two processes, identification and negotiation of meaning. Identification comes from engagement (investing ourselves in our practice, as well as in relations with others), imagination (seeing our experience as part of a broader context- "images of the world that transcend engagement" Wenger 1998: 17) and alignment (connection to others when our practice is in line with a broader enterprise, involving power). Negotiation of meaning involves ownership of making meaning of experience, power processes, and, if the participant's contribution is continually denied, results in marginalisation.

Narrative research has been recognised to be of particular significance in capturing language teacher development (Barkhuizen et al. 2013; Golombek and Johnson 2004; Harbon and Moloney 2013). It is understood that language teaching and learning focus not only on acquisition of a language, but on the interaction and development of a holistic and intercultural identity (Scarino 2013). Gibb (2013) and Liang (2013), for example, have written language teacher narratives featuring the transformative, or 'identity-changing' effect of language learning in their lives, and as they also observe it changing lives in their classroom learners. In our use of narrative enquiry to examine our experiences and trajectories within the CFL community, we have, as noted, endeavoured to avoid essentialization of educational schema (Dervin 2009; 2011). Nevertheless, in individuals' stories, the tension between educational beliefs is noted, for example, between the models of teacher as authoritative source of knowledge (Leng 2005) and of the teacher as facilitator, helping the student to make their own discoveries in learning (Wilson 1996; Honebein 1996).

While the theoretical framework of this study of trajectories considers educator identity, it is relevant to also consider the nature of the community into which the professional 
trajectory is striving to enter, exit, or create. A Community of Practice is "a group of people who share an interest in a domain of human endeavour and engage in a process of collective learning that creates bonds between them" (Wenger 2001: 2). A Community of Practice involves three activities: mutual engagement (collaboration), joint enterprise (learning from each other) and shared repertoire (reflecting on common endeavour). Community of Practice importantly recognises that learning occurs in social relationships, 'concerns the whole person acting in the world' (Lave and Wenger 1991: 49), and considers what kind of community provides a context conducive to learning and change for individual members. Skyrme (2014), for example, has used Wenger's (1998) notions of community to analyse the experience of Chinese undergraduates studying in New Zealand, noting that the process of achieving membership of a community of practice must involve the construction of identities.

\section{Context}

Chinese has emerged as a high-demand language within and beyond the Asia-Pacific region. To accommodate the rapidly increasing number of learners of Chinese globally (Chinese Ministry of Education 2006), many Chinese teacher education programmes were quickly developed both within and outside China in the last few years (Wang et al. 2013). These programs, focused largely on training in linguistics and syntax, together with research in Chinese linguistics, represent the central academic authority in international Chinese language teaching and research. They have given limited attention to creative classroom pedagogy, especially as expected in overseas contexts. They have also featured training in the materials of the International Curriculum for Chinese produced by Hanban (Chinese National Office for Teaching Chinese as a Foreign Language). The suitability of these materials for overseas contexts has been critically questioned (Scrimgeour and Wilson 2009). There is, even within China, no proper Chinese language teacher certification system that meets international standards (Wang 2014). As a result, many young native-speaker Chinese teachers trained in academic programs within China have found it difficult to teach in a way that Western learners can relate to well (Orton 2011).

Meanwhile, a growing number of language teaching experts and language teacher educators, from English-speaking countries or with TESOL background, have been involved in teacher training programmes for CFL. It is suggested that their transferable expertise in language classroom pedagogies and experience in research are what CFL teachers need to learn and acquire. However, due to communication issues, gaps in intercultural understanding, incompatible research paradigms and the like, teachers and teacher educators from non-Chinese backgrounds may find it equally challenging to legitimate the professional role and contribution they can make.

Clearly, all stakeholders may experience dislocation from their original academic training, and struggle to construct a trajectory for themselves in the professional community. The unstable nature of professional trajectories is particularly impeding the sustainable development of Chinese language teaching, however, and thus, the learning outcomes for many young learners. To this end, this study asked two research questions: What can the examination of CFL teacher narratives reveal about teacher 
beliefs and experiences in the professional field? How do these experiences impact their teaching, research, and commitment to the professional community?

The paper will seek to understand the struggles and successes of one Chinese teacher and one language teacher educator, across a four-year collaboration, engaged in communication towards improving their legitimate professional participation.

Author one is currently involved in the tertiary teaching of pedagogical methodology to pre-service language teachers in an Australian university. Previously, she was a teacher of Japanese and French in secondary schools. She has studied Chinese at beginner levels. Author two is a native-speaker Chinese teacher, currently teaching Chinese in a tertiary institute in Hong Kong, who has obtained degrees in Chinese Linguistics studies and English Language Education in Beijing and Hong Kong.

The authors first got to know each other through a journal article of mutual interest. Over the past four years, they have worked collaboratively on two research papers, one conference workshop and developed research agendas on CFL teaching research. During this time, they have learned a great deal reciprocally about each other, and about each other's professional contexts. However, they have shared common concerns and frustrations in their professional participation in the community of global Chinese teaching and learning research. In early 2014, they decided to chart their career trajectories as a means of professional reflection and development, and more importantly, through cross-cultural academic activity, to contribute to East-west discourse development.

\section{Methods}

Qualitative research enquiry into teacher professional practice has commonly employed one of the related modes of self-study, narrative enquiry, life history or auto-ethnography. In the use of such methods to investigate work contexts, Denshire (2014) has particularly highlighted the capacity to "destabilize boundaries between a professional's work and the rest of their life, and break through the dichotomy between selves and others". The element common to all these methodologies is reflection. Reflection attempts to bring coherence to make meaning of experience, using both observation and inference (Dewey 1933/1986), a critical 'conversation' with the self (Schön 1987; 1991), and sometimes, critique of the fundamental assumptions on which our beliefs have been found (Mezirow 1990). Hamilton et al. (2008) represent self-study as a broad field which may use diverse methods to provide the evidence and context for understanding practice. As has been the case in this study, self-study research often begins in discussion that may outline a problem of practice, and then proceeds to select a mode of reflection, in this case, narrative enquiry. Narrative enquiry identifies experience as a story which becomes meaningful through interpretation. The narrative enquiry researcher tracks process, experience and progress of the work through narrative writing. Building on recommendations (Barkhuizen et al. 2013) and the methodology of other studies (e.g. Clandinin and Connelly 2000; Liu and Xu, 2011; Tsui, 2007) this study designed its self-study process into three methodological steps:

(1)Both researchers acted as narrative writers. They independently wrote texts of first person reflective narrative exploring their history and relationship with language 
and culture teaching and learning, and Chinese language teaching in particular.

These texts are the data of the study.

(2)Each researcher individually and alone, read the other's narrative data carefully.

This involved reading and making sense of the narrative data, coding for themes and recurring concepts, and writing up an interpretation.

(3) Using Skype and email communication, the researchers compared their thematic interpretations, engaged in dialogic negotiation, and developed a collaborative analysis. Through categorization and classification, particular instances of events in the data are linked to more general relevant concepts, and relationships can be identified between background influence, community membership and identity. The narratives have been placed within a third person framework of analysis and commentary.

With Armour (2004) we understand that the data are neutral, and it is the analysis, based on researchers' interpretations and perceptions, that reveals aspects of the narrators' identity construction and trajectory.

\section{Analysis of data and findings}

Analysis of Narrative A data

Narrator A describes herself as coming from a "less traditional" Chinese family in Beijing in the 1980s. Her father's job in an international company brought the family lots of opportunities to see and try new things when she was young. She notes:

I can still recall how smart and proud he looked when he was typing English on a typewriter. Growing up in a "modern" family, I am not afraid of trying new things and new ideas, and I see learning English as a fun and life-changing experience.

Narrator A identifies strongly with learning English, which represents to her something foreign, new and useful. However, locally, she "soon tasted disappointment in studying English as a major in a university in Beijing". Her Chinese professors taught strictly by the book, going methodically through vocabulary and exercises in the textbooks, allowing students few opportunities to speak English in class. She was not able to identify herself, or align her imagined bigger picture of what it meant to learn English, with this traditional Confucian pedagogy. However, an important turning-point occurred when she was taught by some Native English Teachers (NETs) from English-speaking countries. These teachers, reconnecting with her initial conception of English as Western, fun, and useful,

... evoked my interest and enthusiasm in learning English, and taught me how to put language into use through engaging activities and authentic materials in life presentation, which has deeply shaped my perspective on teaching. I started to think about being a teacher in the future.

My goal was to be able to teach Chinese in the way that my NET teachers had done, which had motivated me in learning a foreign language.

These role models brought about an investment of the self in her choice of career. They initiate an imagination that Chinese could be taught with the same engaging 
pedagogy to which she had responded so positively in English. She decides to emulate these role models, in positioning her professional identity as a teacher of Chinese as foreign language. She hopes to belong to an imagined community similar to that of the NET models, where alternative pedagogy is the norm. To achieve this goal, she joined a postgraduate programme to become a certified Chinese teacher. She was again faced with a misalignment of her identity, against the other students' credentials, as she was the only student in the programme who had not majored in the first degree in Chinese. This difference in her major, the result of her choice for English study, placed her outside what was positioned as the 'legitimate' identity for a 'good' Chinese teacher. The other students are reflecting the institution's academic approach:

My classmates constantly made me feel that I could never be as legitimate as they were as a teacher of Chinese. In their view, a good Chinese teacher must have a Chinese major and must be able to teach grammar like a living dictionary.

Her peers bring their practice and beliefs 'in line' with the broader institution, whereby the identity of an institution becomes the identity of its conforming participants. This alignment process involves power, which can be adversely exercised towards an outsider whose identity is not "in line". Varghese et al. (2005) suggest that in teaching contexts, issues of access, participation and social engagement are always reflections of larger institutional and national ideologies.

Despite this experience of alienation, Narrator A was one of the few Masters students to get any teaching practice because the faculty needed teachers with good English skills. She found a part-time teaching job which led to a full faculty position in University X. Struggling with her identity process in this environment, however, Narrator A tries to negotiate meaning surrounding her work. She recognizes that her choices, and her knowledge, have placed her outside the officially accredited and valued knowledge.

It soon became clear to me that I was stuck in a "Chinese-English" dilemma. On one hand, I was encouraged to see that my English ability was regarded as valuable asset in building up a good career path. On the other hand, I found that teachers with a non-Chinese major background were largely marginalized in the faculty because senior scholars deemed our knowledge of Chinese as "problematic and less solid" than Chinese major graduates.

Members whose meanings are consistently rejected and whose experiences are considered irrelevant, and hence not accepted as a form of competence, will develop an identity of marginality (Tsui 2007). Narrator A nevertheless shows a sense of agency in continuing to independently develop innovative practice. While her teaching was highly valued in student evaluation surveys, her efforts to improve teaching pedagogy were never taken seriously by senior scholars. Recognising her marginalized identity,

I agonized a long time before I came to a conclusion that the career trajectory to reach full participation in a Chinese academic department was not exactly what I wanted. Even though the community had offered me a qualification to teach and a job in a university, I was not encouraged to offer new thoughts on teaching. 
To innovate in her pedagogy, and to stretch beyond the local, had become the most important elements of her professional engagement, and meaning negotiation. Having this aspect of her professional identity invalidated, Narrator A left the community of University X for a doctoral program in Hong Kong. Narrator A reflects on the change in her teaching philosophy and how the doctoral program changed her perceptions. When she started teaching, she pushed her students to memorize "at least 50 characters a week" and she set up unrealistic goals. But she reflects:

When I look back, I find I was only domesticating my foreign students to be Chinese! Through my doctoral program in Hong Kong, I learnt how to respect individual differences and value the quality of communication in the classroom. I realized I must become a human before I act like a teacher, as teaching is fundamentally a human behavior.

Just as she was negotiating her teacher 'self', and the human relationships involved in teaching, she reports that she started to see the importance of creating meaning, rather than just sentence structure, in her students' learning. Learner construction of meaning through language is a fundamental tenet of Western language education today (Kramsch 1993; 2014). Her pedagogy featured activities and tasks to engage her students in classroom learning and to ensure they could all use the language in the class. Her goal became for them to learn happily and to find learning Chinese meaningful to their personal life and career development.

Narrator A's academic identity is constructed within both Chinese and English, engaged in the East-west discourse. She uses the negative metaphor "trapped" however to denote her lack of agency, in a space which offers her no community, and no sense of being able to access the outbound trajectory she desires:

It sounds promising as a bilingual teacher but most of the time I feel I'm trapped in a limbo. I belong to neither the English nor the Chinese community.

Narrator A writes that she is willing to learn and work hard to achieve full participation in a community that encourages alternative approaches and free expression of research interests. The academic community frustrated her trajectory, however, in not recognizing her to work in a way that engaged her knowledge and identity.

Nevertheless, Narrator A continues to seek a professional community aligned with her practice and identity outside the Chinese academic community. She has written papers in Chinese on problems in pedagogy, but these have attracted skepticism from the community of academic authorities, and positioned as marginal to 'serious' Chinese teaching and learning. In contrast, she has sent English language papers to English journals and they have been published quickly with good impact. This reinforces her perception that her identity and trajectory are exiting from the core CFL community, and heading out towards the international, as this is where they are valued and affirmed.

Narrator A has developed an intellectual independence, and confidence in the value of her innovative teaching philosophy. This has enabled her to understand the difficulty of her students in learning Chinese, and the importance of intercultural communication, not only in the classroom, but also in collaboration with teachers and researchers 
from diverse contexts. This has thrown critical light on her position in the community of Chinese teaching and research.

\section{Analysis of Narrative $B$ data}

Narrator B describes herself as an Angloceltic Australian from a family in which she was the first person to study foreign languages at university. She graduated as a young teacher of French and German in the 1970s. She later took up study of Japanese and negotiated further shift in identity through acquiring her Japanese language self. Armour (2004) has presented an analysis of this dual role of learner-teacher in Narrator B's language learning experience.

She moved into teaching Japanese in the 1990s and became active in the Japanese teacher community, which she found to be friendly, inclusive, and featuring a balance of native/non-native speakers. Through organising exchange programs with Japanese school groups, she developed a commitment to the broader intercultural development she saw in students and their families, where perceptions, bias, and racism, were constantly challenged:

I saw that learning Japanese particularly changed the sometimes insular outlook of Australian children and their families. A critical intercultural approach to life and language learning became important to me, both personally and professionally.

She visited Japan on numerous occasions, for language courses, school trips, and to visit Japanese friends. She writes:

Hindsight may be rose-coloured, but I do not remember anxiety about using my fledgling language, which grew quite rapidly in confidence. I grew into a warm sense of belonging as a competent non-native speaker, with a sense of linguistic and professional agency.

It seems that without tension, Narrator B transferred her teaching style from the European languages to Japanese, albeit with some adaptations, creating activities, games, role-plays, ways of teaching the three scripts, for purposeful enjoyable learning. Japanese was successfully "brought in", integrated and adapted to the constructivist pedagogy of Australian schools. Rightly or wrongly, this model of adaptation served later as the template of her assumption that the same could be achieved in Chinese.

Following doctoral study, Narrator B transitioned to tertiary teaching in language teacher education in 2009. She enjoys teaching languages methodology to a multi-language group of pre-service language teachers and appreciates the responsibility involved, that in training effective language teachers, she is helping children to eventually experience positive language learning in their classrooms:

In my workshops I model the pedagogies of constructivist learning that I want the pre-service teachers to use in their own classes: active group tasks, enquiry learning, critical thinking about culture, games for meaningful language use. I expected, perhaps illogically, that the CFL pre-service teachers could make pedagogical adaptation as I had done in Japanese, even though they were working with a different education schema in their head. 
However, the Chinese pre-service teachers communicated that they had great difficulty in understanding the Australian student, the style of pedagogy she was promoting, and the expected teacher role. With insufficient knowledge of the CFL pre-service teachers' different educational backgrounds, she had made assumptions, arising from her own Western education, as to the teachers' understanding. As she increased her background knowledge of China, she realised the gap between educational schema that made understanding difficult for her students. Narrator B felt dismayed by the findings of a national report on CFL in schools (Orton 2008) which had highlighted the alarming $96 \%$ drop-out rate from CFL studies before the final year of secondary school. The report pointed to pedagogy as one factor in this poor outcome, and difficulties in China-educated teachers adapting to local Australian educational culture. In becoming more deeply involved in CFL teacher training and research, Narrator B had two purposes: as a teacher educator, she cared about the struggles that CFL teachers were experiencing and, as a former classroom teacher, she wanted Australian children to experience the same broadening experience learning Chinese, as she had witnessed in Japanese classrooms.

Narrator B also returned to her earlier role as language learner. Her motivation to study Chinese was both the pleasure of exploring a new language and culture, but also to understand first-hand the challenges in learning Chinese from the Australian learner perspective. As she had also done in Japanese study earlier, in addition to learning language, she immersed herself in reading Chinese fiction in translation.

Together with wide reading and several trips to China, I have acquired beginner level Chinese language. I have achieved only patchy progress, but I love the excitement of a new fledgling language persona.

While some simple language ability served to create links with her pre-service CFL teachers, and created a feeling of personal involvement in her research focus, she understands that that without advanced language competence, she cannot consider herself a scholar in the CFL community. Nevertheless, she hoped to create some form of inbound trajectory into the CFL academic community:

I would like to be, through my investment in CFL teacher training and my research, a peripheral contributor to the CFL community.

A negative turning point in this imagined inbound trajectory into membership of the CFL community, however, has been her attendance at two "international" CFL conferences, one in Australia, one in China. In both instances, she was the only non-Chinese academic there. Every research paper was presented monolingually in Chinese, without translation, bilingual presentation slides or abstracts. She is mindful of the perceived arrogance of the L1 English outlook, and that the lingua franca of the community is clearly Chinese. She notes however that although all delegates also spoke English, and were teaching in diverse Englishspeaking countries, they declined to speak to her:

I have felt alienation, and discouragement through this exclusion. My hoped-for peripheral membership of the community seemed to be not welcome. 
She questioned the value of her work, her alignment with the community, and thought about exiting her CFL research. As an experienced teacher in her previous career, however, Narrator B has already established a professional sense of agency, and felt the 'right' to be at the conference. She felt the agency to take positive action, in suggesting that the CFL community needed to critically reflect:

Perhaps simply by being there, however, it afforded both the community and myself an opportunity to reflect. At the second conference, at the beginning of my presentation session, I spent a few minutes explaining first my linguistic exclusion from the content of the conference, and second, my commitment to CFL teacher training in Australian schools. Following an introduction in Chinese by my research partner, I presented our paper about an intercultural learning task in CFL, which was well received. Some delegates later quietly offered to me their embarrassed realisation that organisers should make conferences (as a representation of their community) more linguistically inclusive.

Despite her negative experience of marginalisation, she still wants her research studies to contribute in the broader CFL teacher community. She continues to build relationships with CFL teachers, and to publish in the area.

\section{Results and discussion}

The two narratives illustrate the complexity involved in professional trajectories in CFL language education. Both narratives provide illustrations of the role that early experiences in language and culture play in shaping identity, beliefs, practice, assumptions and expectations.

In answering our two research questions, our analysis has demonstrated that the examination of CFL teacher narratives can reveal a great deal about the role of individual teacher beliefs and experiences, in the shaping of their trajectories and attitudes. Their beliefs, expectations, and experiences of professional inclusion and exclusion all greatly impact their teaching, their relationships with students, their research choices, and their commitment to the professional community.

Further to this, when we began this study, we believed ourselves to be frustrated, disempowered peripheral members of one large CFL academic community, from which our identities felt marginalised. Through the self-study process, we have come to a transformed understanding that we, like many other CFL practitioners globally, in fact do not have to see our identities as marginalised from one central authority. We represent empowered elements of an emerging diverse and de-centralised CFL teacher community, which is developing many authoritative centres of activity. These decentralised communities are vital to the future of more successful CFL learning. We hope that this small community of two, which in this study has participated in collaboration, joint enterprise, and shared endeavour, contributes to the voices of those centres.

We add here a post-script of two events which have happened since we first constructed the narratives and this article. Narrator A was greatly encouraged in late 2014 by winning a prestigious teaching recognition - Teaching Excellence Award - in the Institute where she practices her alternative CFL teaching methods. Student evaluation results indicated that Narrator A has helped students build confidence in speaking Mandarin Chinese and make Chinese easy and fun to learn. In addition, since 
2014, she has received invitations from universities outside China to give presentations and share experiences based on her studies on Chinese language teacher education. Narrator B has experienced inclusion in new local CFL teacher education communities, such as the Chinese Teacher Training Centre at the University of Melbourne, composed of both Chinese and Australian scholars, with papers conducted bilingually, or largely in English. In her perception, she was included as a member of the group, and her contribution to research was noted. Finally, in light of these later events, we add one last section of dual narrative, written to reflect on the outcomes of our international peer learning experience:

Narrator A

Collaborating with Robyn is my first experience of working with a non- Chinese colleague on Chinese teaching and learning research. Through her, I have learned many useful skills and good attitude and most importantly, I have had a precious opportunity to understand how the two of us differently perceive Chinese teaching. Her comments prompted me to rethink many things that I took for granted, and her tolerant and caring personality makes me, a young teacher, feel respected about what I think. This is a fascinating experience of intercultural professional learning.

\section{Narrator B}

Working with Danping, over the long gestation of this project, has been important to me in "filling the gaps" in my understanding of CFL, in a number of ways. Firstly, it shifted stereotypes I had held, such as "all Chinese teachers think and teach this way", when clearly Danping refreshingly didn't think or teach that way at all! Secondly it revealed to me my arrogant assumptions, arising from my own unexamined educational background, as to how CFL teachers should be adapting to the Australian school context. I love the personal challenge, that in all intercultural work, the self becomes visible, and it isn't always comfortable. Just as I have been defined as an East-coast white Australian, by Aboriginal Western Australians, it sharpened my recognition of the shaping of my educational beliefs by my educational heritage. And finally it made me aware of the global potential for improving language teacher education, through individual interaction in international peer collaboration and research.

We are encouraged also by the rapid changes emerging in the last few years in the research literature. This is marked by studies of new pedagogy (Singh and Han 2014), studies of CFL teacher identities (e.g. Wang and Du 2014) and writing which represents critical enquiry into essentialized positions in Chinese studies (e.g., Dervin 2009; 2011). This study has illustrated the impact of the two individuals' identification and negotiation of meaning regarding their career trajectories in the CFL community. Assymetrical power relations have at times created identities of marginalisation. But through our collaboration, and the formation of new communities, we have increased our ownership of "meanings", our sense of agency, and our negotiation of our place.

\section{Conclusion}

Global changes affect both educational demand and academic life, and change the way teachers and teacher educators think about their identities, pedagogy and professional 
encounters (Hellstén and Goldstein-Kyaga 2011). This self-study project has similarly been pushed by the need for pedagogic critique in the internationalisation of Chinese language teaching and learning. While two case studies cannot be generalised, we suggest that the study has 'generative power' (Wardekker 2000). Narrative enquiry has the "power to enlighten people by making them really understand the narratives that were the object of the study" (p.266). With Wardekker (2000), we believe that this may lead to understanding of change processes in a specific situation, which creates a "potential for learning and change" (Wardekker 2000: 269).

The study suggests the potential for all CFL teachers to explore critical perceptions of changes in their identities and their pedagogies, and where their shifting identity may 'fit', in the shifting CFL teaching community. Self-study, interpreting each other's stories, and the extensive dialogue which has taken place around this writing, has offered us a creative space to change our perceptions of the tensions existing in the academic CFL community. Self-study has acted both as a methodology and a process in this work. These self-study narratives have confirmed for us the role of investigation of personal experience in the shaping of identity, values, attitudes and practice, in our professional development. They secondly offer insight through our own experiences, into struggles being played out in CFL teaching today. We have found ourselves able to challenge the supposed authority of a central CFL discipline, in our different capacities, and able to construct independent trajectories.

Our experience in this self-study is a microcosm of a larger phenomenon rapidly developing. In addition to the need for dispersed centres of innovative CFL practice, we also recognise that as more university students globally graduate with Chinese majors, there will be an increasing number of non-native CFL teachers, who will want a valid role and identity in their own innovative CFL communities. CFL teacher training needs to prepare the type of teachers who can deal educationally with transnational and local diversity (Luke 2004), with a range of adopted and adapted pedagogies to use. Just as it is accepted that TESOL practice has developed as a de-centralised transnational polyglot endeavour (Canagarajah 2006), we predict that multiple CFL communities are becoming autonomous, diverse, and flexible entities. The field is changing rapidly, with new practice as noted evolving on many fronts (Moloney and Xu 2015).

Constructing de-centralised communities places responsibility on us, as individual community members, as we consider the implications of our study for our practice in teacher education, and teaching, respectively. First, Author 1 intends to encourage in her CFL pre-service teachers, self-study critical examination of the East-west discourse, involving beliefs about culture, language and practice, adaptation in CFL pedagogies, and to support mentoring development with local teachers. In the case of teaching CFL, Author 2 recognises her leadership in pursuing and modelling independent innovative practice, to support and prioritise her students' learning. We look to contributing, whether it is provided live or online, to the creation of relevant local CFL professional development, to support innovation, and teacher confidence, and to pursue further research in tracking and linking the multiple new CFL centres of teacher development.

Finally, within a de-centralised community taking a post-modern turn, we look towards Hirst and Brown's (2008) suggestion that in communities of mature practice, there would be an acceptance and expectation that members' efforts undergo critical 
comment and that individuals communicate with each other as equals. It is to open this communication that we have offered our self-study, to contribute to the CFL teacher knowledge base. The communication is picking up pace, and we look towards its innovative output.

\section{Competing interest}

The authors declare that they have no competing interests.

\section{Authors' contributions}

Both RM and DW conceived of the study, designed the methodology and participated equally in the analysis and writing. Both authors participated equally in writing the manuscript. Both authors read and approved the final manuscript.

\section{Author details}

${ }^{1}$ School of Education, Faculty of Human Sciences, Macquarie University, Balaclava Rd, North Ryde, NSW 2109, Australia. ${ }^{2}$ Department of General Education, Technological and Higher Education Institute of Hong Kong (Thei), 20A Tsing Yi Road, Tsing Yi, NT, Hong Kong.

Received: 25 October 2015 Accepted: 30 January 2016

Published online: 14 April 2016

\section{References}

Armour, W. (2004). Becoming a Japanese language learner, user and teacher: Revelations from life history research. Journal of Languages, Identity, and Education, 3(2), 101-125.

Barkhuizen, G, Benson, P, \& Chik, A. (2013). Narrative inquiry in language teaching and learning research. London: Routledge.

Ben-Peretz, M. (2011). Teacher knowledge: What is it? How do we uncover it? What are its implications for schooling? Teaching and Teacher Education, 27(1), 3-9.

Canagarajah, S. (2006). TESOL at forty: What are the issues? TESOL Quarterly, 40(1), 9-34.

Canagarajah, S. (2012). Teacher development in a global profession: An autoethnography. TESOL Quarterly, 46(2), 258-279.

Chiang, Y. (2010). Native Chinese language teachers' beliefs and experiences on their teaching in the U.S (EdD Dissertation). St. Paul: St Thomas University.

Chinese Ministry of Education. (2006). The report of the language situation in China (Year 2005). Beijing: Commercial Press.

Clandinin, J, \& Connelly, M. (2000). Narrative inquiry: Experience and story in qualitative research. San Francisco: Jossey-Bass.

Cole, D, \& Meadows, B. (2013). Avoiding the Essentialist trap in intercultural education: Using critical discourse to read nationalist ideologies. In F. Dervin \& A. Liddicoat (Eds.), Linguistics for Intercultural Education (pp. 29-48). Amsterdam: John Benjamin Publishing Company.

Bucholtz, M, \& Hall, K. (2004). Language and identity. In A. Duranti (Ed.), A companion to linguistic anthropology (pp. 369-394). Oxford: Blackwell.

Cummins, J. (1996). Negotiating identities: Education for empowerment in a diverse society. Ontario: California Association for Bilingual Education.

Deng, Z. (2011). Confucianism, modernization and Chinese pedagogy: An introduction. Journal of Curriculum Studies, 43(5), 561-568.

Denshire, S (2014). On auto-ethnography. Current Sociology Review, 62(6), 831-850.

Dervin, F. (2009). The solidification of Chineseness in academic mobility: Critical reviews of 'intercultural' research articles on Chinese students (CAFIC Conference Paper).

Dervin, F. (2011). A plea for change in research on intercultural discourses: A 'liquid' approach to the study of the acculturation of Chinese students. Journal of Multicultural Discourse, 6(1), 37-52.

Dewey, J. (1933/1986). How we think: A restatement of the relation of reflective thinking to the educative process. In J. A. Boydston (Ed.), The later works of John Dewey (pp. 96-109). Carbondale Southern: Illinois University Press.

Gibb, B. (2013). Eyes wide opened. In L. Harbon \& R. Moloney (Eds.), Language teachers' narratives of practice (pp. 158-166). Cambridge: Cambridge Scholars Publishing.

Golombek, PR, \& Johnson, KE. (2004). Narrative inquiry as a mediational space: Examining emotional and cognitive dissonance in second language teachers' development. Teachers and Teaching, 10(3), 307-327.

Goodson, I. (2003). Professional knowledge, professional lives. McGraw-Hill Education (UK).

Hamilton, ML, Smith, L, \& Worthington, K. (2008). Fitting the methodology with the Research: An exploration of narrative, self-study and auto-ethnography. Studying Teacher Education: A Journal of Self-study of Teacher Education Practices, 4(1), 17-28.

Hall, S. (1990). Cultural identity and diaspora. In J. Rutherford (Ed.), Identity, community, culture difference (pp. 222-237). London: Lawrence \& Wishart.

Harbon, L, \& Moloney, R. (Eds.). (2013). Language Teachers' Narratives of Practice. Cambridge: Cambridge Scholars Publishing.

Hellstén, M, \& Goldstein-Kyaga, K. (2011). Negotiating intercultural academic careers: A narrative analysis of two senior university lecturers. In S. Trahar (Ed.), Learning and teaching narrative inquiry: Travelling in the Borderlands (pp. 157-172). Amsterdam: John Benjamins Publishing.

Hirst, E, \& Brown, R. (2008). Pedagogy as dialogic relationship. In M. Hellstén \& A. Reid (Eds.), Researching international pedagogies: Sustainable practice for teaching and learning in higher education (pp. 179-202). Netherlands: Springer.

Honebein, P. (1996). Seven goals for the design of constructivist learning environments. In B. Wilson (Ed.), Constructivist learning environments: Case studies in instructional design (pp. 11-24). Englewood Cliffs: Educational Technology.

Hu, G. (2002). Potential cultural resistance to pedagogical imports: the case of communicative teaching in China. Language Culture and Curriculum, 15(2), 93-105. 
Kanno, Y. (2003). Imagined communities, school visions, and the education of bilingual students in Japan. Journal of Language, Identity, and Education, 2(4), 285-300.

Kleinsasser, RC. (2013). Language teachers: Research and studies in language(s) education, teaching, and learning. Teaching and Teacher Education, 29, 86-96.

Kramsch, C. (1993). Context and culture in language teaching. Oxford: Oxford University Press.

Kramsch, C. (2014). Teaching foreign languages in an era of globalization: Introduction. The Modern Language Journal, 98(1), 296-311.

Lave, J, \& Wenger, E. (1991). Situated learning: Legitimate peripheral participation. Cambridge: Cambridge University Press.

Lave, J, \& Wenger, E. (2002). Legitimate peripheral participation in communities of practice. In R. Harrison (Ed.), Supporting lifelong learning: Perspectives on learning (pp. 111-126). London: Routledge Falmer.

Leng, H. (2005). Chinese cultural schema of education: Implications for communication between Chinese students and Australian educators. Issues in Educational Research, 15(1), 17-36.

Liang, JL. (2013). One teacher's exploration of the personal and professional. In L. Harbon \& R. Moloney (Eds.), Language teachers' narratives of practice (pp. 120-127). Cambridge: Cambridge Scholars Publishing.

Liu, Y, \& Xu, Y. (2011). Inclusion or exclusion?: A narrative inquiry of a language teacher's identity experience in the 'new work order' of competing pedagogies. Teaching and Teacher Education, 27(3), 589-597.

Luke, A. (2004). Teaching after the market: From commodity to cosmopolitan. The Teachers College Record, 106(7), 1422-1443.

Ma, W (Ed.). (2014). East meets West in teacher preparation: Crossing Chinese and American borders. New York: Teachers College Press.

Mezirow, J. (1990). How critical reflection triggers transformative learning. In J. Mezirow (Ed.), Fostering critical reflection in adulthood (pp. 1-20). San Fransisco: Jossey-Bass.

Moloney, R. (2013). Providing a bridge to intercultural pedagogy for native speaker teachers of Chinese in Australia. Language, Culture and Curriculum, 26(3), 213-228.

Moloney, R, \& Xu, HL. (Eds.). (2015). Exploring Innovative pedagogy in the Teaching and Learning of Chinese as a Foreign Language. Singapore: Springer Publishing.

Moloney, R, \& Xu, HL. (2012). We are not teaching Chinese kids in Chinese context, we are teaching Australian kids in Australian schools. In M. K. Aishah et al. (Eds.), Culture in foreign language learning: Framing and reframing the issue (pp. 470-487). Singapore: NUS Centre for Language Studies.

Norton, B (2000). Identity and language learning: Gender, ethnicity and educational change. CABA: Editorial Dunken.

Orton, J. (2008). Report on Chinese education in Australian schools. Melbourne: University of Melbourne.

Orton, J. (2011). Educating Chinese Language teachers - Some fundamentals. In L. Tsung \& K. Cruikshank (Eds.), Teaching and learning Chinese in global contexts (pp. 151-164). London: Continuum.

Scarino, A (2013). Foreword. In L. Harbon \& R. Moloney (Eds.), Language teachers' narratives of practice (pp. xiii-xviii). Cambridge: Cambridge Scholars Publishing.

Schön, D. (1987). Educating the reflective practitioner. San Francisco: Jossey-Bass.

Schön, D. (1991). The reflective practitioner: How professionals think in action. Aldershot: Ashgate Publishing.

Scrimgeour, A, \& Wilson, P. (2009). International Curriculum for Chinese Language Education. Babel, 43(3), 35-37.

Singh, M, \& Han, J. (2014). Educating teachers of "Chinese as a local/global language": Teaching Chinese with Australian characteristics. Frontiers of Education in China, 9(3), 403-428.

Skyrme, G. (2014). Being Chinese or being different: Chinese Undergraduates use of discourses of Chineseness. Frontiers of Education in China, 9(3), 303-326.

Sun, D. (2012). "Everything goes smoothly": A case study of an immigrant Chinese language teacher's personal practical knowledge. Teaching and Teacher Education, 28(5), 760-767.

Tsui, A. (2007). Complexities of identity formation: A narrative inquiry of an EFL teacher. TESOL Quarterly, 41(4), 657-680.

Varghese, M., Morgan, B., Johnston, B., \& Johnson, K. A. (2005). Theorizing language teacher identity: Three perspectives and beyond. Journal of language, Identity, and Education, 4(1), 21-44.

Wang D. (2014) English in the Chinese foreign language classroom. Frankfurt am Main: Peter Lang; 2014

Wang, D, Moloney, R, \& Li, Z. (2013). Towards internationalising the curriculum: A case study of Chinese language teacher education programs in China and Australia. Australian Journal of Teacher Education, 38(9), 116-135.

Wang, L, \& Du, X. (2014). Chinese Teachers' professional identity and beliefs about the teacher-students' relationships in an intercultural context. Frontiers of Education in China, 9(3), 429-455.

Wardekker, WL. (2000). Criteria for the quality of inquiry. Mind, Culture, and Activity, 7(4), 259-272.

Wenger, E. (1998). Communities of practice: Learning, meaning, and identity. Cambridge: Cambridge University Press.

Wenger E: Supporting communities of practice: A survey of community-oriented technologies. [http://wenger-trayner.com/ introduction-to-communities-of-practice/]; 2001. Accessed 16 June 2015.

Wilson, BG. (1996). Constructivist learning environments: Case studies in instructional design. New Jersey: Educational Technology.

Zhang, $\sqcup, \&$ Zhang, D. (2015). Identity matters: An ethnography of two Nonnative English- Speaking Teachers (NNESTs) struggling for legitimate professional participation. In Y. L. Cheung, S. Said, \& K. Park (Eds.), Advances and current trends in language teacher identity research (pp. 116-131). London: Routledge. 